\title{
Early results of colorectal cancer treated with robotic surgery: A single-center experience
}

\author{
Yılmaz Özdemir, ${ }^{1}$ A Ayetullah Temiz²
}

'Department of Gastroenterology Surgery, Health Sciences University, Erzurum Regional Training and Research Hospital, Erzurum, Turkey

${ }^{2}$ Department of General Surgery, Health Sciences University, Erzurum Regional Training and Research Hospital, Erzurum, Turkey

\begin{abstract}
Introduction: Colorectal cancer is the third most common cancer among adults and one of the most common malignancies seen in developed countries. The use of robotic surgical systems in minimally invasive procedures has many potential advantages. Unlike the two-dimensional (D) visual images provided by modern laparoscopic systems, robotic systems provide a continuous 3D image and a sense of depth, especially for surgeons familiar to traditional open surgery. In this study, it was aimed to present the early results of patients who underwent robotic surgical resection for colorectal cancer.
\end{abstract}

Materials and Methods: The patient files of 33 colorectal cancer patients, who had been treated with robotic surgery, between September 2015 and June 2019, were retrospectively reviewed. Age, gender, tumor location, surgery performed, duration of surgery, intraoperative blood loss, post-operative histopathological findings, length of hospital stay, morbidity, and mortality were recorded.

Results: The mean age of the patients was $66.78 \pm 12.11$ years. Of the patients, $17(51.5 \%)$ were male. The rectum was the most common localization (66.5\%). The most common procedure performed was low anterior resection $(n=12)$. The mean blood loss was $195.45 \pm 62.95 \mathrm{~mL}$ and the mean operative time was $315.24 \pm 92.40 \mathrm{~min}$. No complications developed intraoperatively in any of the patients. A total of four patients were converted to open surgery. Post-operative complications occurred in three patients. The average length of stay was $6.22 \pm 1.08$ days. In the histopathological evaluation, the mean total number of lymph nodes removed was $15.8 \pm 3.4$, and the mean number of pathological lymph nodes was $1.54 \pm 0.6$. The most common tumor stage was, Stage $3(48.4 \%)$. There was no positive surgical margin in any of the patients.

Conclusion: Due to the articulating instruments and advanced imaging technology used in robotic surgery, dissection of the tissues for total mesorectal excision can be performed more easily and effectively in colorectal cancers. In this way, better quality resection and lymph node dissection can be performed and more accurate staging and appropriate oncological results can be obtained.

Keywords: Colorectal cancer, robotic surgery, total mesorectal excision

\section{Introduction}

Colorectal cancer is the third most common cancer among adults and one of the most common malignancies seen in developed countries. Approximately 1 million colorectal cancer diagnoses are made each year worldwide, while 500.000 patients die from colorectal cancer. ${ }^{[1,2]}$ Current treatment is based on a multidisciplinary approach that included surgery, chemotherapy, and radiotherapy. Sur- 
gery can be performed by open and minimally invasive methods. Laparoscopic surgery for colorectal cancer has gained momentum since the promising results of the first laparoscopic colectomy in $1991 .{ }^{[3]}$ In recent years, huge steps have been taken, especially in the field of laparoscopic surgery, and the technical limitations that have emerged with the wide spread use of laparoscopy have brought the use of robotic surgical systems to the forefront. The use of robotic surgical systems in minimally invasive procedures has many potential advantages. Unlike the two-dimensional (2D) visual images provided by modern laparoscopic systems, robotic systems provide a continuous 3D image and a sense of depth, especially for surgeons familiar to traditional open surgery. In addition, these robotic systems offer the surgeon the advantage of continuity in their procedures through their robotic tireless arms.

In this study, it was aimed to present the early results of patients who underwent robotic surgical resection for colorectal cancer.

\section{Materials and Methods}

The medical files of 33 colorectal cancer patients who had been treated with robotic surgery, between September 2015 and June 2019, were retrospectively reviewed. Age, gender, tumor location, surgery performed, duration of surgery, intraoperative blood loss, post-operative histopathological findings, length of stay, and morbidity, and mortality were recorded.

\section{Working Principle of the Da Vinci Robotic System}

Components of the Da Vinci XI Surgical System (da Vinci Xi Surgical System Intuitive Surgical, Sunnyvale, CA, USA).

\section{The Console}

Here, the surgeon's hands are placed on the controller to create a surgical interface with the computer. The next part of the console is the 3D imaging system. There are two arms and four pedals used to focus the camera and manipulate robotic arms and tools.

\section{The Imaging System}

This is a system consisting of dual light sources and dual cameras with three integrated circuits. The dual camera is mounted at the end of the endoscope to provide 3D view- ing. The 12-mm telescope is accompanied by two independent 5-mm telescopes.

\section{The Arms}

The last component of the robotic system is the patient part. There are three robot arms holding the instruments and one arm in the center that holds the camera. There are four specially designed multi-joint robot arms that can move in a manner similar to the natural human hand. The tips of the instruments are designed to give the surgeons natural dexterity and an even wider range of motion than the human hand. This allows the robotic arms to maneuver in a way that simulates human movements. These instrumental wrists restore a full range of motion in seven dimensions and are capable of rotating $540^{\circ}$ and articulating $180^{\circ}$.

\section{Surgical Technique}

Bowel preparation was performed on all of the patient's before surgery. The operations were performed according to the total mesorectal excision (TME) principles. A standardized medial to lateral approach was used. The right ileocolic artery and right branch of medial colic artery and veins were cut and clipped with high ligation for right-sided colon tumors. The dissection was carefully performed to avoid injury to the third and fourth continents of the duodenum. All anastomoses were made intracorporeally. The specimen was removed from a supra-umbilical incision. For left-sided colon and rectum tumors, high ligation of the inferior mesenteric artery was performed. The inferior mesenteric vein was clipped under the pancreas and cut. Sharp pelvic dissection was performed using monopolar coagulation, bipolar, and ultrasonic energy devices, depending on the situation. Dissection was performed to the pelvic floor. In cases where anastomosis was performed, the rectum was cut with endoscopic staplers, and the specimen was removed from a suprapubic incision. An intracorporeal anastomosis was performed with a double stapler by transanal insertion of a circular stapler. Anastomosis was checked by a transanal air-water test. In risky anastomoses, such as low rectal anastomosis and in patients with neoadjuvant radiation, temporary loop ileostomy was additionally performed. In abdominoperineal resections (APRs), after pelvic dissection, the rectum was excised and end colostomy was performed on the left side of the abdomen. The specimen was then resected through transanal dissection. 


\section{Statistical Analysis}

Data were analyzed using SPSS Statistics for Windows 15.0 (SPSS Inc., Chicago, IL, USA). Categorical variables were expressed as the number (n) and percentage (\%). Numerical variables were expressed as the mean \pm standard deviation and the student t-test was used to compare the means of two independent groups. $\mathrm{P}<0.05$ was considered statistically significant.

\section{Results}

The mean age of the patients was $66.78 \pm 12.11$ years. Of the patients, 17 (51.5\%) were male and 16 (48.5\%) were female. The most common localization for tumor was the rectum (66.5\%), comprising cecum (9.1\%), rectosigmoid (6.1\%), sigmoid (6.1\%), ascending colon (6.1\%), transverse colon (3.1\%), and splenic flexure (3.1\%), respectively. Low anterior resection $(n=12)$ was the most common procedure performed, followed by APR $(n=10)$, right hemicolectomy $(n=5)$, anterior resection $(n=3)$, left hemicolectomy $(\mathrm{n}=2)$, and extended right hemicolectomy $(\mathrm{n}=1)$. The mean blood loss was $195.45 \pm 62.95 \mathrm{~mL}$ and the mean operative time was $315.24 \pm 92.40 \mathrm{~min}$. No complications developed intraoperatively in any of the patients. A total of four patients were converted to open surgery. The reasons for the transition to open surgery comprised being unsure about the safety of the surgical margin in two patients, tumor invasion to the bladder in one patient, and diffuse intraperitoneal adhesions in one patient. Post-operative minor complications developed in three patients, of whom two had wound infection and the other had atelectasis. There was no mortality. The average length of stay was $6.22 \pm 1.08$ days. The characteristics of the patients treated with robotic surgery are given in Table 1 . In the histopathological evaluation, the mean total number of lymph nodes removed was $15.8 \pm 3.4$, and the mean number of pathological lymph nodes was $1.54 \pm 0.6$. There were no positive surgical margins in any of the patients. The most common tumor stage was Stage 3 (48.4\%), followed by Stage 2 (24.2\%), Stage $1(24.2 \%)$, and Stage 0 (12.1\%). The histopathological results of the patients are given in detail in Table 2 .

\section{Discussion}

The Da Vinci S Surgical System, which is accepted as the current robotic surgery system, was put into use in the surgical field after its approval by the FDA in 2000. Minimally invasive resection is preferred more often when compared to open surgery, due to decreased postoper-
Table 1. Characteristics of patients treated with robotic surgery

\section{Demographics Characteristics}

n (\%)

\section{Gender \\ Male \\ Female}

$17(51.5)$

$16(48.5)$

Age, years, mean $\pm S D$

$66.78 \pm 12.11$

Tumor Location

Cecum

Ascending colon

Transverse colon

$1(3.1)$

Splenic flexure

Sigmoid colon

Rectosigmoid colon

Rectum

$22(66.5)$

Operative procedure

Right hemicolectomy

5 (15.2)

Extended right hemicolectomy

Left hemicolectomy

Anterior resection

$3(9.1)$

Low anterior resection

$12(36.4)$

Abdominoperineal resection

Causes of Conversion

Surgical margin safety in distal

rectal tumor

Bladder Invasion

Intraabdominal Adhesion

Postoperative complications

Wound infection

$10(30.3)$

Atelectasis

2

Mean blood loss, mean \pm SD

Average operation time, min,

mean $\pm S D$

Average length of stay, day,
mean \pm SD

$195.45 \pm 62.95$

$315.24 \pm 92.40$

1

1

2

1

ative pain, hospital stay, and morbidity, and improved patient satisfaction with similar oncological results.[4] With the application of robotic surgery, significant developments have been made in colorectal surgery in recent years. Additional benefits of robotic surgery systems to laparoscopic surgery comprise it providing 3D imaging, increased freedom of movement due to the ability to rotate on its own axis at the tip of the robotic instruments, and the opportunity to easily perform complex operations, especially in narrow areas, which may be difficult from time to time, even in open surgery. ${ }^{[5]}$ 
Table 2. Histopathological Results of the Patients

n (\%)

\begin{tabular}{|c|c|}
\hline \multicolumn{2}{|l|}{ Tumor histopathology } \\
\hline Adenocarcinoma & 31 (93.9) \\
\hline Intramucosal carcinoma & $1(3)$ \\
\hline $\begin{array}{l}\text { No tumor (Pathological } \\
\text { complete response) }\end{array}$ & $1(3)$ \\
\hline Tumor size, $\mathrm{cm}$, mean $\pm S D$ & $5.8 \pm 2.9$ \\
\hline $\begin{array}{l}\text { Average number of lymph } \\
\text { nodes removed, mean } \pm S D\end{array}$ & $15.8 \pm 3.4$ \\
\hline \multicolumn{2}{|l|}{ Tumor Differentiation } \\
\hline Low & $2(6.1)$ \\
\hline Moderately & $26(78.8)$ \\
\hline Well & $5(15.2)$ \\
\hline Lymphovascular Invasion & $16(48.5)$ \\
\hline Perineural Invasion & $13(39.4)$ \\
\hline \multicolumn{2}{|l|}{ pT } \\
\hline TO & $1(3)$ \\
\hline $\mathrm{T} 1$ & $2(6.1)$ \\
\hline $\mathrm{T} 2$ & $8(24.2)$ \\
\hline T3 & $19(57.6)$ \\
\hline $\mathrm{T} 4$ & $3(9.1)$ \\
\hline \multicolumn{2}{|l|}{$\mathrm{pN}$} \\
\hline No & $17(51)$ \\
\hline N1 & $14(42)$ \\
\hline N2 & $2(6)$ \\
\hline \multicolumn{2}{|l|}{ pTNM stage } \\
\hline 0 & $1(3)$ \\
\hline 1 & $8(24)$ \\
\hline II & $8(24)$ \\
\hline III & $16(48)$ \\
\hline IV & $0(0)$ \\
\hline
\end{tabular}

In the surgical treatment of colorectal cancer, when the post-operative advantages of minimally invasive surgery are combined with the technical advantages provided by the robot, better patient satisfaction and oncological results can be achieved with robotic surgery. ${ }^{[6]}$ Compared to open surgery, rectal surgery is clearly more demanding and permanent due to the localization of the rectum and the narrow anatomical structure of the pelvis. Despite numerous notable advances in instrumentation and imaging techniques, laparoscopic TME for rectal cancer in the narrow pelvis is still difficult due to the use of joint less laparoscopic instruments. ${ }^{[7]}$ The use of robots in colorectal surgery was first reported by Ballantyne et al. in 2009.
${ }^{[8]}$ TME is based on the excision principle with ligation of the mesocolon from the point where the colonic vessels are branched. For ligation, careful dissection is required to clearly visualize the central vessels. Compared to laparoscopy, these surgical steps are performed more easily and more effectively with robotic surgery.

The number of lymph nodes dissected is an important marker for the prognosis of the disease. ${ }^{[9]}$ The TME is considered as a prerequisite procedure, as it reduces local recurrence by $4-6 \% \cdot{ }^{[10-12]}$ The mean number of lymph nodes removed in robotic surgery in a series of 44 patients by De Souza et al. ${ }^{[13]}$ was 14 , and the average number of lymph nodes removed during robotic surgery in a series of 143 patients by Pigazzi et al. ${ }^{[14]}$ was 14.1. In two studies comparing laparoscopic and robotic surgery, the average number of lymph nodes removed laparoscopically was 11.2-14.2, and in robotic surgery it was 10.3-17.3. ${ }^{[15,16]}$ The average number of lymph nodes removed in the current study was 15.6, which was consistent with the studies in the literature.

In studies comparing robotic and laparoscopic surgery, mean blood loss, mean operation time, conversion rates, anastomotic leaks, and morbidity rates were found to be similar. In two studies, the mean operation time in patients treated with robotic surgery was $231.9-240 \mathrm{~min}$, the average hospitalization time was 6.5-9.9 days, there were no conversions to open surgery, the anastomotic leakage rate was $5.6-9.7 \%$, and the morbidity rate was $16-29.3 \%$, while in laparoscopic surgery, the mean operative time was 168.6-237 min, mean hospitalization time was 6-9.4 days, conversion rate was $0-4 \%$, and the anastomotic leak rate was 7.3-8\% 23.2-24. ${ }^{[16,17]}$ In addition, in the study of Leong et al., ${ }^{[18]}$ the mean operative time in operations performed with robotic surgery was $325 \mathrm{~min}$ and the mean hospitalization time was 9 days. In the study of Yang et al., comparing robotic, laparoscopic, and open surgery, the mean operation times were 169,135 , and $148 \mathrm{~min}$, the mean blood loss was 104, 146, and $205 \mathrm{~mL}$, and the mean number of lymph nodes removed was 13,11 , and 10, respectively. Compared to open and laparoscopic surgery in the literature, mean operative time is generally against robotic surgery. The most important reason for this is early learning and inexperience. ${ }^{[19,20]}$

In two studies in the literature, the mean blood loss was 50-283 mL. ${ }^{[16,15]}$ Conflicting results have been reported in studies comparing robotic and laparoscopic rectal surgery with regard to the mean blood loss. In a comparative 
study, the mean blood loss was higher in robot-assisted surgery when compared to laparoscopic-assisted surgery, but the result was not significant (137.4 vs. 127). ${ }^{[15]}$ In general speaking, the different published studies report statistically significant differences in favor of robotic surgery, both with respect to open and laparoscopic surgery. ${ }^{[2-23]}$ In the present study, in the first series of 33 patients, the mean operation time was $315 \mathrm{~min}$, the mean blood loss was $155 \mathrm{~mL}$, the rate of conversion was $12 \%$, and the morbidity rate was $9 \%$. Colonic fistula did not develop in any of these patients postoperatively, and all of the results were consistent with the literature.

\section{Conclusion}

Due to the experience that was gained in this study, and the articulating instruments and advanced imaging technology used in robotic surgery, dissection was able to be performed more easily and effectively in TME in colorectal cancers. In this way, adequate staging can be achieved with better quality resection and lymph node dissection and appropriate oncological results can be obtained.

\section{Disclosures}

Ethichs Committee Approval: The Ethics Committee of Erzurum Regional Training and Research Hospital provided the ethics committee approval for this study (02.11.2020-2020/199).

Peer-review: Externally peer-reviewed.

Conflict of Interest: None declared.

Authorship Contributions: Concept - Y.Ö., A.T.; Design - Y.Ö., A.T.; Supervision - Y.Ö.; Materials - Y.Ö.; Data collection and/or processing - Y.Ö., A.T.; Analysis and/ or interpretation - Y.Ö.; Literature search - Y.Ö., A.T.; Writing - Y.Ö.; Critical review - Y.Ö., A.T.

\section{References}

1. Winawer SJ. The multidisciplinary management of gastrointestinal cancer. Colorectal cancer screening. Best Pract Res Clin Gastroenterol 2007;21:1031-48. [CrossRef]

2. Siegel RL, Miller KD, Fedewa SA, Ahnen DJ, Meester RGS, Barzi A, et al. Colorectal cancer statistics, 2017. CA Cancer J Clin 2017;67:177-93. [CrossRef]

3. Hoffman GC, Baker JW, Doxey JB, Hubbard GW, Ruffin WK, Wishner JA. Minimally invasive surgery for colorectal cancer. Initial follow-up. Ann Surg 1996;223:790-6. [CrossRef]

4. Alimoğlu O, Atak İ, Eren T, Kılıç A. Robot assisted laparoscopic (RAL) gastrectomy: Case series and a review of the literature. Ulus Cerrahi Derg 2013;29:187-91. [CrossRef]
5. Wilson EB. The evolution of robotic general surgery. Scand J Surg 2009;98:125-9. [CrossRef]

6. Ballantyne $\mathrm{GH}$. Robotic surgery, telerobotic surgery, telepresence, and telementoring. Review of early clinical results. Surg Endosc 2002;16:1389-402. [CrossRef]

7. Wexner SD, Bergamaschi R, Lacy A, Udo J, Brölmann $H$, Kennedy $\mathrm{RH}$, et al. The current status of robotic pelvic surgery: Results of a multinational interdisciplinary consensus conference. Surg Endosc 2009;23:438-43. [CrossRef]

8. Ballantyne $\mathrm{GH}$, Merola P, Weber A, Wasielewski A. Robotic solutions to the pitfalls of laparoscopic colectomy. Osp Ital Chir 2001;7:405-12.

9. Chang GJ, Rodriguez-Bigas MA, Skibber JM, Moyer VA. Lymph node evaluation and survival after curative resection of colon cancer: Systematic review. J Natl Cancer Inst 2007;99:433-41. [CrossRef]

10. Wynn GR, Austin RC, Motson RW. Using cadaveric simulation to introduce the concept and skills required to start performing transanal total mesorectal excision. Colorectal Dis 2018;20:496-501. [CrossRef]

11. Chen $C C$, Lai $Y L$, Jiang JK, Chu $C H$, Huang IP, Chen WS, et al. Transanal total mesorectal excision versus laparoscopic surgery for rectal cancer receiving neoadjuvant chemoradiation: A matched case-control study. Ann Surg Oncol 2016;23:1169-76. [CrossRef]

12. Chouillard E, Regnier A, Vitte RL, Bonnet BV, Greco V, Chahine E, et al. Transanal NOTES total mesorectal excision (TME) in patients with rectal cancer: Is anatomy better preserved? Tech Coloproctol 2016;20:537-44. [CrossRef]

13. deSouza AL, Prasad LM, Marecik SJ, Blumetti J, Park JJ, Zimmern A, et al. Total mesorectal excision for rectal cancer: The potential advantage of robotic assistance. Dis Colon Rectum 2010;53:1611-7. [CrossRef]

14. Pigazzi A, Luca F, Patriti A, Valvo M, Ceccarelli G, Casciola L, et al. Multicentric study on robotic tumor-specific mesorectal excision for the treatment of rectal cancer. Ann Surg Oncol 2010;17:1614-20. [CrossRef]

15. Patriti A, Ceccarelli G, Bartoli A, Spaziani A, Biancafarina A, Casciola L. Short-and medium-term outcome of robot-assisted and traditional laparoscopic rectal resection. JSLS 2009;13:176-83.

16. Park JS, Choi GS, Lim KH, Jang YS, Jun SH. Robotic-assisted versus laparoscopic surgery for low rectal cancer: Casematched analysis of short-term outcomes. Ann Surg Oncol 2010;17:3195-202. [CrossRef]

17. Bianchi PP, Ceriani C, Locatelli A, Spinoglio G, Zampino MG, Sonzogni A, et al. Robotic versus laparoscopic total mesorectal excision for rectal cancer: A comparative analysis of oncological safety and short-term outcomes. Surg Endosc 2010;24:2888-94. [CrossRef]

18. Leong QM, Son DN, Cho JS, Baek SJ, Kwak JM, Amar AH, et al. Robot-assisted intersphincteric resection for low rectal cancer: Technique and short-term outcome for 29 consecutive patients. Surg Endosc 2011;25:2987-92. [CrossRef]

19. Grass JK, Perez DR, Izbicki JR, Reeh M. Systematic re- 
view analysis of robotic and transanal approaches in TME surgery a systematic review of the current literature in regard to challenges in rectal cancer surgery. Eur J Surg Oncol 2019;45:498-509. [CrossRef]

20. Eltair M, Hajibandeh S, Hajibandeh S, Nuno A, Abdullah $\mathrm{KH}$, Alkaili-Alyamani $A$, et al. Meta-analysis and trial sequential analysis of robotic versus laparoscopic total mesorectal excision in management of rectal cancer. Int $\mathrm{J}$ Colorectal Dis 2020;35:1423-38. [CrossRef]

21. Tang B, Gao GM, Zou Z, Liu DN, Tang C, Jiang QG, et al. Efficacy comparison between robot-assisted and laparoscopic surgery for mid-low rectal cancer: A prospective randomized controlled trial. Zhonghua Wei Chang Wai Ke Za Zhi 2020;23:377-83.

22. Ng KT, Tsia AK, Chong VY. Robotic versus conventional laparoscopic surgery for colorectal cancer: A systematic review and meta-analysis with trial sequential analysis. World J Surg 2019;43:1146-61. [CrossRef]

23. Lee SH, Kim DH, Lim SW. Robotic versus laparoscopic intersphincteric resection for low rectal cancer: A systematic review and meta-analysis. Int J Colorectal Dis 2018;33:174153. [CrossRef] 